\title{
Analysis of Defogging Performance, Thermal Comfort, and Energy Saving for HVAC System Optimization in Passenger Vehicles
}

\author{
Taro Ono ${ }^{1, *}$, Hideaki Nagano $^{1}$, Suguru Shiratori ${ }^{1}$, Kenjiro Shimano ${ }^{1}$, and Shinsuke Kato ${ }^{2}$ \\ ${ }^{1}$ Tokyo City University, Graduate School of Integrative Science and Engineering, 1-28-1, Tamadutsumi, Setagaya, Tokyo, Japan \\ ${ }^{2}$ The University of Tokyo, the Institute of Industrial Science, 4-6-1, Komaba, Meguro, Tokyo, Japan
}

\begin{abstract}
The heating, ventilation, and air-conditioning (HVAC) system in a vehicle is used for both defogging the windshield and ensuring the thermal comfort of passengers. A challenge is that energy savings in the HVAC system lead to decreased system performance. The three objective functions, i.e. defogging performance, thermal comfort, and energy savings, these must be considered in parallel to find the optimized control strategy. In the present study, a transient numerical simulation of the in-vehicle environment is performed and the dependency of performance on the air flow rate and supplied air temperature is analyzed. The criteria of defogging performance and thermal comfort are determined as the constrained conditions. The results show a trade-off relationship between the air flow rate and air temperature in defogging performance and thermal comfort; however, their sensitivities depend on the conditions and the time elapsed. As for transient defogging performance, the air flow rate has greater impact than airflow temperature. The air flow rate and the air temperature are comparable in their effects on equivalent temperature, which is employed as the index of the thermal environment. The blowing condition range that fulfills the criteria makes a transition to a low-energy condition with time elapsed. A control strategy for the air flow rate and temperature is derived considering the transient and steady-state conditions.
\end{abstract}

\section{Introduction}

In recent years, electric vehicles (EVs) have been attracting attention as a measure against environmental problems. EVs continue to face various problems which prevent them from becoming popular. One problem is a decline in cruising distance when the heating, ventilation, and air-conditioning (HVAC) system is used because it consumes a significant amount of energy from the battery. Therefore, energy savings in the system are required. However, if the energy of the HVAC system is saved more than required, there is concern that fogging on the windshield or reduced passenger thermal comfort could result. The three aspects of the HVAC system must be considered in the design phase for both the vehicle and the HVAC system. The purpose of this study is to determine optimal conditions for the HVAC system in order to fulfil the three aspects of defogging performance, thermal comfort, and reduced energy consumption. In this study, we focus on controlling two conditions, the air flow rate and supplied air temperature, by means of software with a conventional hardware system. The optimized strategy for controlling the blowing condition can be derived based on the simulation results.

First, the evaluation of defogging performance is described. This considers performance in terms of removing fog from the driver's visible area in a short time.
In order to evaluate this performance, it is necessary to consider the cause of windshield fogging. This is a complicated phenomenon affected by the flow field of the entire interior of the vehicle and water vapor transport; however, the most dominant element among these factors is the blowout airflow from the defroster. Aroussi (2003) et al. presented a numerical model to simulate the airflow velocity in the vicinity of the windshield surface and the temperature distribution on the windshield as a model for defrosting and demisting systems [1]. Many such studies on simulating defogging systems by numerical calculations have been done. In addition, Shojaeefard et al. determined the relevant area for judging defogging performance on the windshield and evaluated from the temperature distribution on the windshield using computational fluid dynamics (CFD) [2]. In the present study, the defogging performance is evaluated as the defogged area on a windshield predicted by numerical simulation. The surface temperature and the airflow velocity have dominant impacts on water vapor transport in the vicinity of the windshield surface. Therefore, in this report, the fogging distribution is estimated from the temperature distribution on the windshield and the distribution of water vapor transported by the flow field. In order to evaluate both required performance aspects, the time rate of change of the fogging distribution on the windshield is obtained by unsteady analysis. Hence, we evaluate defogging

* Corresponding author: g1881017@,tcu.ac.jp 
performance by comparing the fogging proportions within the minimum viewing area necessary for operation after a certain period of time.

A method of evaluating passenger comfort is described as follows: although the most popular evaluation index is the predicted mean vote (PMV), this approach assumes that conditions do not differ from a steady, uniform environment and a thermally neutral condition [3]. It is open to argument as to whether the index could be applied to in-vehicle environments, which are unsteady and nonuniform. Kubota (2018) et al. developed an estimation model for thermal sensation using equivalent temperature. The results showed a correlation between the time rate of change of thermal sensation in an experiment and the calculated equivalent temperature [4]. Therefore, in this study, the equivalent temperature based only on physical parameters is used. The value is calculated from the heat dissipation of a thermal manikin. The amount of heat transfer from the manikin depends on the environmental conditions.

Finally, energy saving performance is evaluated using the air-conditioning load used to secure defogging performance and thermal comfort. As a model for predicting the air-conditioning load, Mohammad (2013) et al. proposed a heat balance method modelling heat loss caused by radiation, convection, and conduction in a vehicle [5]. In the present study, numerical simulation of the in-vehicle environment is performed. The influences of ventilation, body heat transmission from inside to outside, the metabolic rate of passengers, and so on are considered in the simulation results. The air-conditioning load is estimated from the temperature difference between the inlet and the outlet, which reflects the various factors of the in-vehicle environment.

An unsteady simulation is performed in order to evaluate the time rates of change for both defogging performance and thermal comfort. The results are compared with steady-state performance investigated by the authors [6]. The discussion clarifies the time rates of change of the performance and the optimum conditions.

\section{Approach}

\subsection{Method for evaluating defogging performance}

For the evaluation of defogging performance, we use the time rate of change of the fogging distribution on the windshield obtained by unsteady analysis. As air conditioning is not used as the initial condition, the interior of the vehicle is cooled and analysis begins from the state where the whole windshield is fogged. Then, the fogging distribution after a certain time has elapsed is confirmed and the degree of fogging in the minimum necessary operating visible area is evaluated as defogging performance. The following subsections explain how to calculate the fog distribution on the windshield and the defogging performance evaluation area.

\subsubsection{Method for determining the fogging distribution}

This section shows a method for determining the fogging distribution on the windshield in the numerical simulation. As a method of determining fogging in the numerical simulation, the dew-point temperature, which is calculated from the air temperature and the relative humidity near the windshield surface, is compared to the surface temperature. When the surface temperature is lower than the dew-point temperature, fogging occurs. The calculation formula for the dew-point temperature is as follows:

$$
\begin{gathered}
T_{d}=\frac{237.3 \times \log _{10} \frac{P_{w}}{0.611}}{7.5-\log _{10} \frac{P_{w}}{0.611}} \\
P_{w}=P_{s} \times \frac{\phi}{100} \\
p_{s}=0.611 \times 10^{\frac{7.5 T}{237.3+T}}
\end{gathered}
$$

where $T_{\mathrm{d}}$ : dew-point temperature $\left[{ }^{\circ} \mathrm{C}\right]$

$P_{\mathrm{w}}$ : water vapor pressure $[\mathrm{kPa}]$

$P_{\mathrm{s}}:$ saturated steam pressure $[\mathrm{kPa}]$

$\varphi$ : relative humidity $[\%]$

$T_{\mathrm{a}}$ : air temperature $\left[{ }^{\circ} \mathrm{C}\right]$

Eqn. (3) is Tetens' equation [7], which is an approximate expression for obtaining the saturated water vapor pressure for a given air temperature.

\subsubsection{Defogging performance evaluation area}

In order to evaluate the defogging performance, we set the area of the windshield in which there must be almost no fogging for driving visibility. This was based on Japanese defroster standards [8]; the windshield was divided into three areas. Figure 1 shows the defogging performance evaluation area. One of the areas, Area A, is at the center of the driver's visible area and thus this area must have almost no fogging. The evaluation criteria using this evaluation area are determined. In order to evaluate the defroster performance needed to clear fogging quickly from Area A, it is considered that more than $90 \%$ of the fogging in Area A after ten minutes must be removed, referring to the defroster standard. In addition, as a reference, defroster standards of the EU [9] and USA [10] were investigated; this found that the method of setting the test area and the evaluation standard are different in the EU and the USA from those in Japan. However, it is common that the test area is defined as the area required for driver visibility, and that the evaluation criterion is that almost no fogging must occur in the area after several tens of minutes have elapsed. 
The authors estimated roughly the defogging performance using 1D simulation [6]. The dew-point temperature was calculated from the blowing condition. The inside surface temperature of the windshield was estimated on the assumption that the heat flow from the inside to the outside was constant in the steady state. Fogging occurred when the surface temperature was lower than the dew-point temperature. This was the simple defogging criterion used in the steady-state calculation.

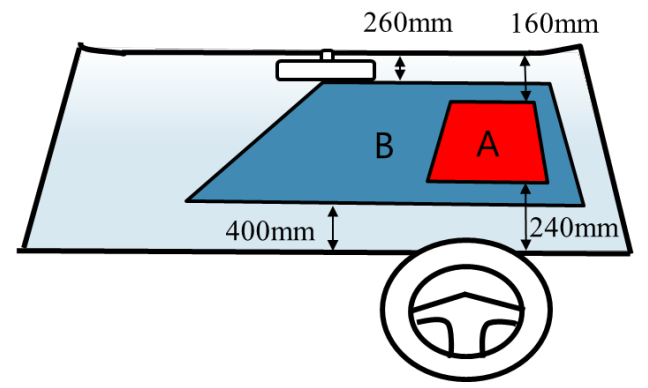

Fig. 1 Test Area

\subsection{Method of evaluating thermal comfort}

According to the definition of the equivalent temperature [11], which is an index based on skin temperature and heat transfer from human to the environment, the equivalent temperature can be adopted only in a steady-state environment. When unsteadiness of the environment is considered, the skin temperature and heat transfer change in association. These reflected the changes in the thermal environment. In the present study, a fixed value of the heat flux was assumed as the boundary condition; then the skin temperature could be varied for a transient environment. The equivalent temperature is determined for the transient thermal environment.

$$
T_{e q}=T_{s k}-\frac{q_{s k}}{h_{c a l}}
$$

where $\quad T_{\mathrm{eq}}$ : Equivalent temperature $\left[{ }^{\circ} \mathrm{C}\right]$

$T_{\text {sk }}:$ Skin temperature $\left[{ }^{\circ} \mathrm{C}\right]$

$q$ : Heat flux from the manikin surface $\left[\mathrm{W} / \mathrm{m}^{2}\right]$

$h_{\text {cal }}$ : Combined heat transfer coefficient in a standard environment $\left[\mathrm{W} /\left(\mathrm{m}^{2} \mathrm{~K}\right)\right]$

$8.0 \mathrm{~W} /\left(\mathrm{m}^{2} \mathrm{~K}\right)$ was employed as the value of $h_{\text {cal }}$ for the sitting manikin [12].

A constraint condition for the thermal comfort evaluation is required; however, no standard is defined for the equivalent temperature. According to Tanabe et al. [13], there is a linear relationship between the equivalent temperature and the PMV. In the present study, PMV is calculated from the equivalent temperature and the targeted range is $\mathrm{PMV}= \pm 0.5$ as recommended by the ISO standard. For calculating PMV, some environmental factors must be considered: relative humidity of $50 \%$, average wind speed of $0.1 \mathrm{~m} / \mathrm{s}$, metabolic rate of 1.0 met, and clothing amount of 1.09 clo, assuming a typical winter season [14]. The air temperature and the average radiant temperature are assumed to be equal to the equivalent temperature. Conversion from the transient equivalent temperature to PMV assumes heat balance of human at every moment. Figure 2 shows the relationship between equivalent temperature and PMV. The equivalent temperature in the range of $\mathrm{PMV}= \pm 0.5$ is in the range from $20.9^{\circ} \mathrm{C}$ to $24.7^{\circ} \mathrm{C}$. The range is employed as a constraint condition to satisfy the thermal comfort of passengers.

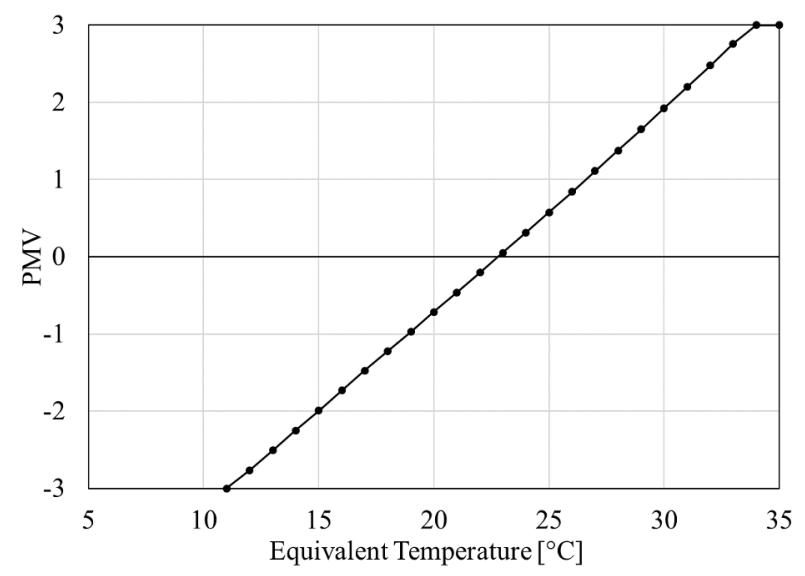

Fig. 2 Relationship between equivalent temperature and PMV

\subsection{Method for evaluating energy savings}

For the evaluaton of energy savings, only the condition with the lowest energy consumption among the conditions satisfying the required defogging performance and thermal comfort was taken as the condition satisfying energy savings performance. In order to evaluate the performance of air conditioning, only the air-conditioning load among the energy consumption amounts was compared. The air-conditioning load represents the amount of heat loss from the air flowing in from the inlet until it flows out through the outlet. 


\section{Analysis}

\subsection{Analysis object}

The blowing conditions were investigated in order to assure the optimum conditions for all three aspects. The range of the air flow temperature was from $30^{\circ} \mathrm{C}$ to $50{ }^{\circ} \mathrm{C}$ and the air flow rate ranged from $60 \mathrm{~m}^{3} / \mathrm{h}$ to $240 \mathrm{~m}^{3} / \mathrm{h}$. For the output of results, the dimensionless value of the axis was used. The dimensionless value of the axis was divided by the difference between the minimum value and the maximum value. Figure 3 shows the non-dimensional blowing condition assumed for the use of winter heating shown in Fig. 3. However, calculating all conditions in Fig. 3 incurs a high computational load. Therefore, instead of calculating all cases, we calculated only the eight cases shown in Table 1 and estimated the others' evaluations from the relationship between the eight calculated cases.

The target space was a $1,350 \mathrm{~mm}$ (width) $\times 2,175 \mathrm{~mm}$ (length) $\times 1,050 \mathrm{~mm}$ (height) standard vehicle cabin model. The grid shape is trihedral grid and the total number of cells is set to about 5.5 million. A grid arrangement is shown in Fig. 4. The grid dependency and verification with the experimental data have been invesitaged [15]. As the air-heating mode in the winter condition assumed, high-temperature air from inlets is considered (Def, Vent and Foot).

Table 1 Calculation cases

\begin{tabular}{|c|c|c|c|c|c|c|c|c|}
\hline & Case1 & Case2 & Case3 & Case4 & Case5 & Case6 & Case7 & Case8 \\
\hline $\begin{array}{c}\text { Flow rate } \\
{\left[\mathrm{m}^{3} / \mathrm{h}\right]}\end{array}$ & \multicolumn{2}{|c|}{60} & \multicolumn{2}{|c|}{100} & \multicolumn{2}{|c|}{180} & \multicolumn{2}{|c|}{240} \\
\hline $\begin{array}{c}\text { Temperature } \\
{\left[{ }^{\circ} \mathrm{C}\right]}\end{array}$ & 30 & 50 & 30 & 50 & 30 & 50 & 30 & 50 \\
\hline
\end{tabular}

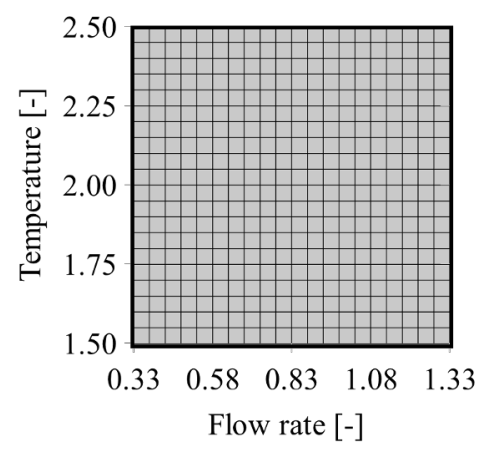

Fig. 3 Non-dimensionalized blowing conditions

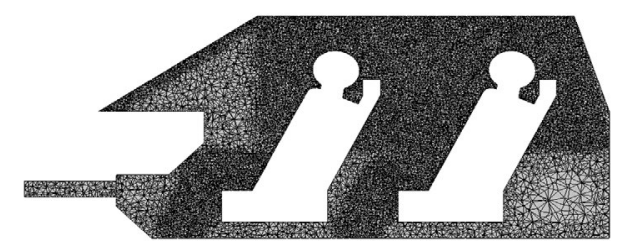

Fig. 4 Computational grid arrangement

\subsection{Calculation condition}

It is assumed in analysis that the number of passengers was four and winter heating in the inside air circulation mode. The inside air recirculation mode was set to $30 \%$ inside air and $70 \%$ outside air. The external environment was assumed to be a winter rainy day and an air temperature of $4{ }^{\circ} \mathrm{C}$ and a relative humidity of $100 \%$ were set. The air-conditioning method was performed in DefFoot mode. In order to simulate the difference in thermal resistance of each parts in the vehicle, each was classified as glass, body, side/rear glass, ceiling, or floor surface and other parts were set as adiabatic surfaces. Table 2 shows the wall boundary conditions.

For the human body, the human body calorific value was always constant at $100 \mathrm{~W}$ per person. All human water vapor was generated from the mouth and the water vapor generation rate was $0.071 \mathrm{~g} / \mathrm{h}$ as the total of exhalation and insensible water loss.

The initial conditions of the analysis were as follows.

The air temperature in the vehicle and the wall surface temperature were $4{ }^{\circ} \mathrm{C}$ and the humidity was $0.011 \mathrm{~kg} / \mathrm{kg}$ ', which means that the total water vapor from the four people generated in one minute was uniformly diffused into the vehicle.

Table 3 shows the calculation conditions, which were as follows.

The incompressible Reynolds-averaged Navier-Stokes equations, continuity equation, chemical species transport equation, and average heat transfer equation were used as governing equations. The standard $k-\varepsilon$ model was used as the turbulence model and standard wall functions were used for near-wall treatment. The buoyancy term was set on the basis of the Boussinesq approximation. Radiation was calculated using a surface-to-surface model. The time step size was $1 \mathrm{~s}$ and the number of time step size was 1,800 .

The evaluation position of the environment to which the occupant was exposed, which is necessary in calculating the equivalent temperature, was taken as the average value of the surface uniformly $40 \mathrm{~mm}$ away from the human body surface, considering the boundary layer around the human body. Figure 5 shows the evaluation area.

Table 2 Wall boundary condition

\begin{tabular}{|c|c|c|c|c|}
\hline & $\begin{array}{c}\text { Thickness } \\
{[\mathrm{mm}]}\end{array}$ & $\begin{array}{c}\text { Heat } \\
\text { conductivity } \\
{[\mathrm{W} /(\mathrm{m} \cdot \mathrm{K})]}\end{array}$ & $\begin{array}{c}\text { Convection } \\
\text { heat transfer } \\
\text { coefficient }\left[\mathrm{W} /\left(\mathrm{m}^{2} \cdot \mathrm{K}\right)\right]\end{array}$ & $\begin{array}{c}\text { Heat transfer } \\
\text { coefficient } \\
{\left[\mathrm{W} /\left(\mathrm{m}^{2} \cdot \mathrm{K}\right)\right]}\end{array}$ \\
\hline Windshield & 6.5 & 0.9 & 60 & 41.96 \\
\hline Ceiling & 15.5 & 0.024 & 59 & 1.51 \\
\hline Side-body & 12.2 & 0.083 & 59 & 4.47 \\
\hline Side-glass & 2.5 & 0.9 & 59 & 50.69 \\
\hline Floor & 12.0 & 0.020 & 59 & 1.62 \\
\hline Rear-glass & 2.5 & 0.9 & 58 & 49.95 \\
\hline Rear-wall & 8.5 & 0.083 & 45 & 8.02 \\
\hline
\end{tabular}


Table 3 Calculation conditions

\begin{tabular}{|c|c|}
\hline Calculation software & Fluent 17.0 \\
\hline \multirow{2}{*}{$\begin{array}{c}\text { Governing } \\
\text { equation }\end{array}$} & $\begin{array}{c}\text { Equation of continuity } \\
\text { Incompressibility RANS } \\
\text { equation }\end{array}$ \\
\cline { 2 - 2 } & $\begin{array}{c}\text { Heat transfer equation } \\
\text { Chemical species transport } \\
\text { equation }\end{array}$ \\
\hline Turbulence model & Standard k- $\varepsilon$ model \\
\hline Wall & Standard wall function \\
\hline Algorithm & PISO \\
\hline \multirow{2}{*}{ Difference scheme } & $\begin{array}{c}\text { Second-order upwind } \\
\text { difference }\end{array}$ \\
\hline Time-dependency & Unsteady \\
\hline Buoyancy & $\begin{array}{c}\text { Boussinesq } \\
\text { approximation }\end{array}$ \\
\hline Radiation & S2S (surface to surface) \\
\hline Time step & $1 \mathrm{~s}$ \\
\hline Number of time steps & $1800 \mathrm{~s}$ \\
\hline
\end{tabular}
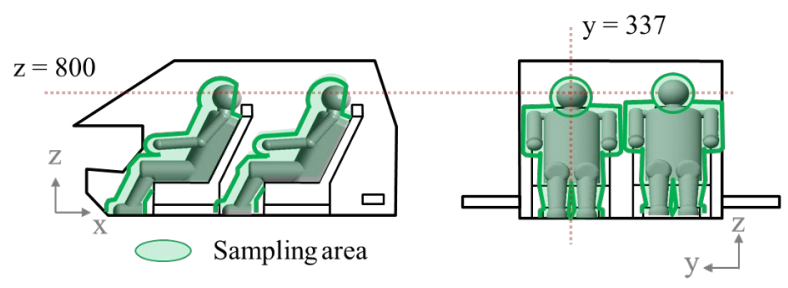

Fig. 5 Evaluation area

\section{Results and discussion}

\subsection{Defogging performance}

Figure 6 illustrates the fogging distribution 10 mins after the start of running. The results show the tendency of a smaller fogging area with a higher airflow rate. As the temperature of the blown air is high, that is, as the surface temperature of the windshield increases, the area of the fogging decreases. Figure 7 shows the temporal change of the defogged area as the area ratio of Area A. The values are plotted every minute from the beginning to 10 mins and every 5 min after 10 mins. The red dotted line in the figure shows a borderline with a defogged area of $90 \%$, which was the evaluation criterion. The blowing conditions satisfying the evaluation criteria of defogging performance were Cases 4, 6, 7, and 8. When comparing Case 3 with Case 4, which had the same air flow rate conditions, only Case 4 with higher air temperature satisfied the criterion. Even though Case 5 had a higher air flow rate than that of Case 4, Case 5 did not satisfy the criterion. Therefore, the threshold value that satisfies the defogging performance was in the vicinity of the middle air flow rate. It seemed that there was the tendency for criteria to be satisfied as blowing air temperature increased.
In order to clarify the threshold curves which separate fogging and defogging blowing condition. The defogging performance over the state space needs to be estimated. Figure 8 shows the blowing conditions that can defog $90 \%$ or more in Area A, the defogged area ratio which was linearly interpolated for all cases and then the values of all blowing conditions are plotted in the nondimensional 2D space shown in Fig. 3.

The threshold values of the blowing condition needed to fulfill the defogging criteria were clarified. The conditions of a middle air flow rate at a high temperature or a high air flow rate at a low temperature are required for defogging. Sensitivity to temperature was relatively high in the range of non-dimensional air flow rate of 0.33 to 0.83 . On the other hand, the air flow rate a great impact on defogging below the non-dimensional temperature of 2.25.

Figure 9 shows the evaluation of defogging performance in the steady state. A larger range of blowing conditions could achieve the defogging criterion in the transient calculation after 10 mins had elapsed. Non-dimensional air flow rates below 0.58 could not defog in either the transient or steady states. As for the low-temperature condition, the range of fulfilled the criterion of air flow rates in the steady state was wider than that in the transient state. This indicates that the air flow rate could be decreased with time when the temperature was fixed.

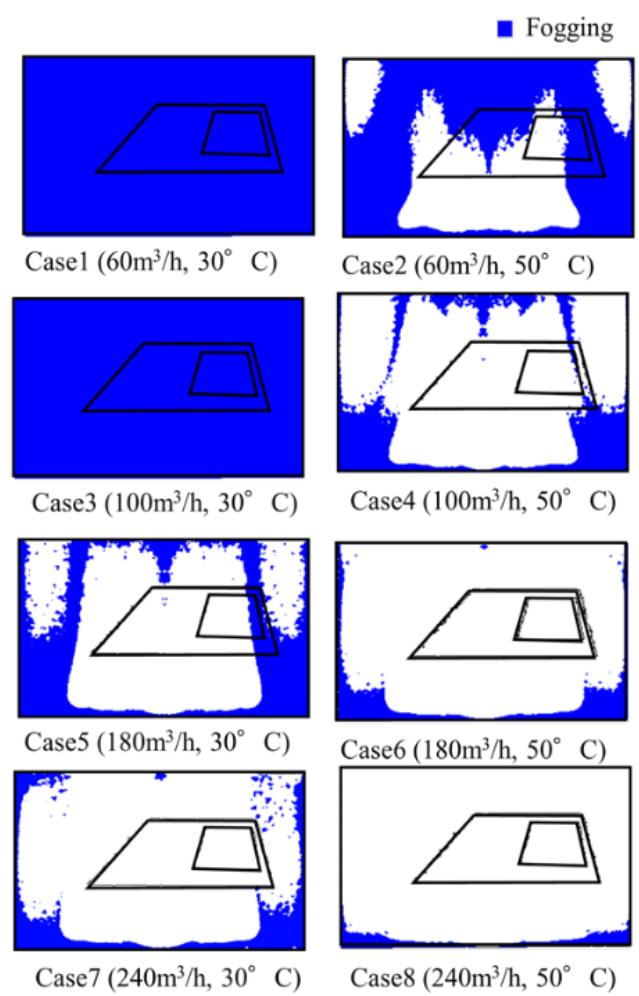

Fig. 6 Fogging distribution after 10 mins 


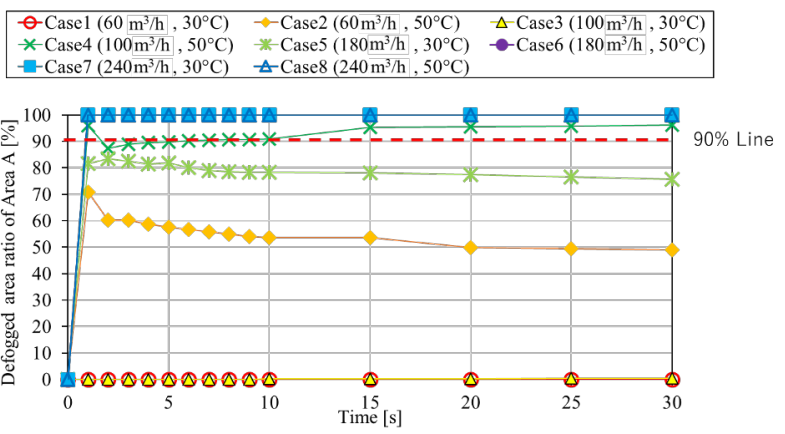

Fig. 7 Time rate of change of defogged area ratio for Area A

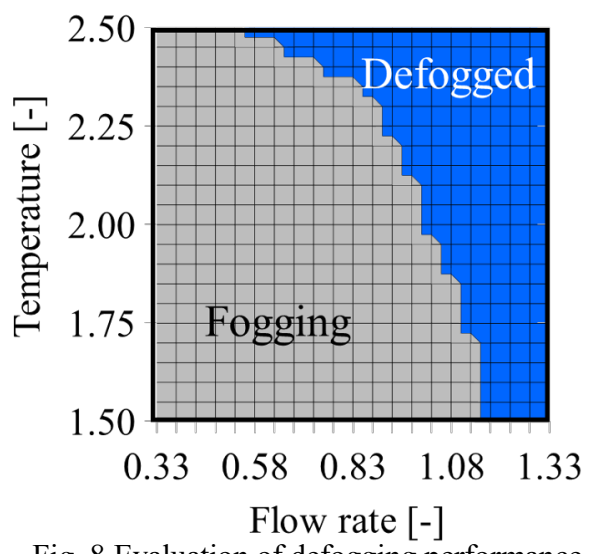

Fig. 8 Evaluation of defogging performance after 10 mins

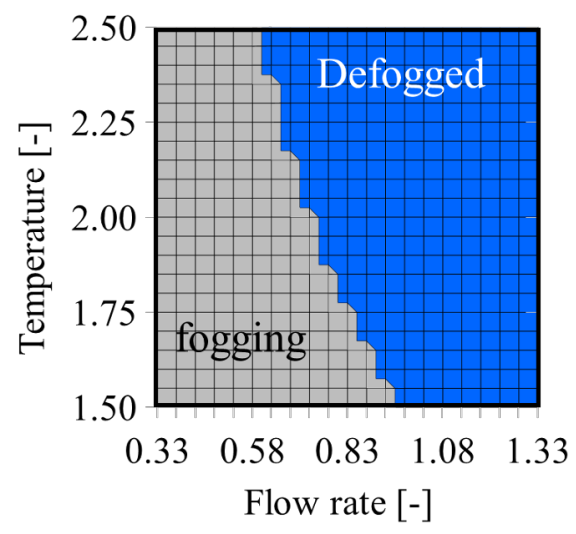

Fig. 9 Evaluation of defogging performance in the steady state

\subsection{Thermal comfort}

Figures 10 and 11 show the time rates of change of the equivalent temperature for the front-seat and rear-seat passengers, respectively. The range surrounded by the red dotted line shows a PMV within \pm 0.5 . The equivalent temperature achieved stability at a nearly constant value in the first several minutes.

Only Case 6, which had a medium air flow rate and a high temperature, achieved a comfort zone for all passengers after 10 mins had elapsed.

As for the differences between passenger seats, the equivalent temperature of the driver in the front seat was higher than that for the passenger in the rear seat at every time. The reason is the front seat was near the air inlet and the driver was exposed to high-temperature air.

Equivalent temperature after $10 \mathrm{mins}$ for all blowing conditions were estimated using linear interpolation and the blowing conditions that satisfied the evaluation criterion of thermal comfort were determined. The results are shown in Figure 12. The area in red indicates the blowing conditions that ensure thermal comfort. The threshold of the blowing conditions satisfying thermal comfort tends to be at a high air flow rate and a high airflow temperature. At lower airflow conditions than the threshold, the equivalent temperature was low and the passenger would experience a cold environment. Regarding conditions higher than the threshold, the equivalent temperature was higher than PMV +0.5 and the air-conditioning system was considered to be wasting energy. As for the dependency of the equivalent temperature on the blowing conditions, the air flow rate and the airflow temperature had almost the same impact on the equivalent temperature.

The results of thermal comfort evaluation of the steady state are shown in Figure 13. The conditions of ensuring thermal comfort in the steady state are larger than those after 10 mins. As for thermal comfort, there are two thresholds corresponding to the positive and negative values of PMV. Even if a target condition could be secured after 10 mins, it could not be satisfied after achieving a steady state. The blowing condition needs to be controlled from the beginning with a high air flow rate and a high temperature until attaining the steady state with a middle range of the blowing condition.

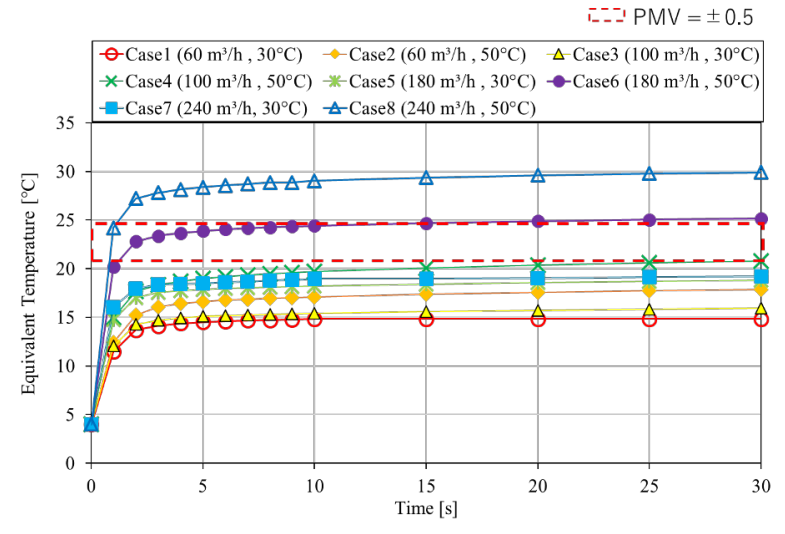

Fig. 10 Time rate of change of equivalent temperature for the front-seat passenger 


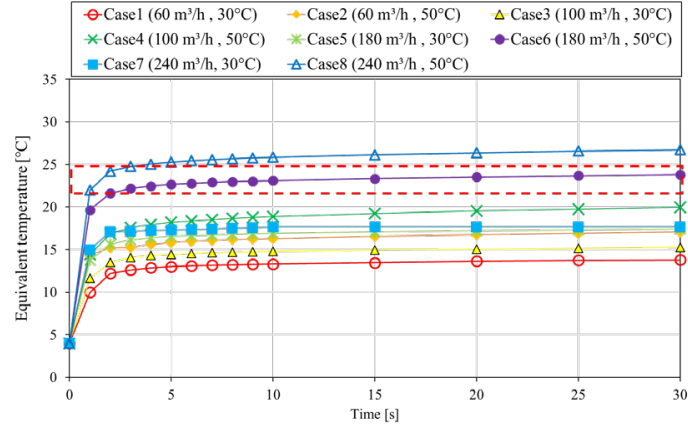

Fig. 11 Time rate of change of equivalent temperature for the rear-seat passenger

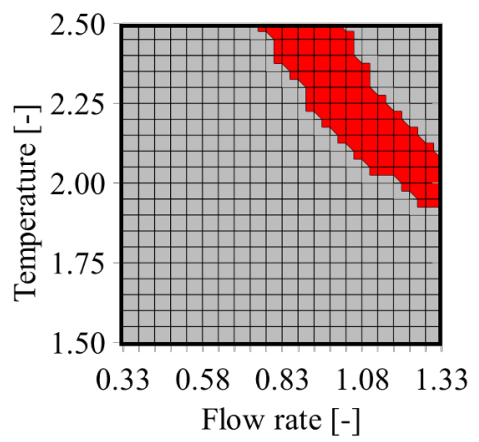

Fig. 12 Evaluation of thermal comfort of after 10 mins

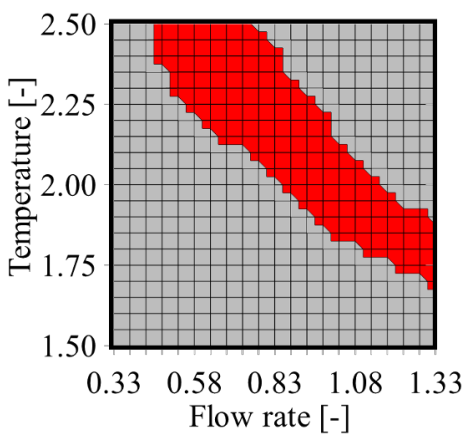

Fig. 13 Evaluation of thermal comfort in the steady state because energy for the air temperature's increase in the vehicle is required during the transient period. The optimized condition is determined from the blowing conditions that fulfil both the required defogging performance and thermal comfort. Figure 16 shows the blowing condition that achieves both defogging performance and thermal comfort. Conditions capable of assurer thermal comfort are included in the conditions that can ensure defogging performance and conditions that satisfy both are the same as those satisfying thermal comfort. The optimal blowing condition among the tested conditions occurred at an air flow rate of $202 \mathrm{~m}^{3} / \mathrm{h}$ and an airflow temperature of $41{ }^{\circ} \mathrm{C}$. The amount of energy consumed in that condition was 1,132 W. As shown in Fig. 16 , under the conditions discussed in the present study, air conditioning at a high air flow rate with a medium airflow temperature 10 mins after the beginning of operation was the optimized condition.

Figure 17 shows the optimum conditions for the steadystate calculation. The optimum condition in the steady state was attained at an air flow rate of $125 \mathrm{~m}^{3} / \mathrm{h}$ and an airflow temperature of $43{ }^{\circ} \mathrm{C}$. The amount of energy consumed in that condition was $635 \mathrm{~W}$. The airflow temperature conditions of the transient and steady-state were almost the same but the required air flow rate in the transient period was greater than that in the steady state. In conclusion, one simple control strategy is proposed: using an airflow temperature fixed at around $40{ }^{\circ} \mathrm{C}$ throughout running and using an air flow rate decreased from $200 \mathrm{~m}^{3} / \mathrm{h}$ at the beginning to $125 \mathrm{~m}^{3} / \mathrm{h}$ as the steady state is attained.

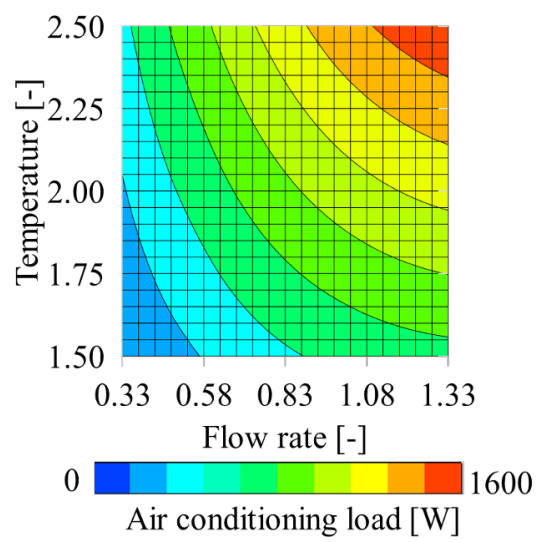

Fig. 14 Amount of energy Consumed after 10 mins

\subsection{Energy saving}

Energy savings performance was evaluated using the value of the air-conditioning load after $10 \mathrm{mins}$ had elapsed. Figure 14 shows the contour map of the airconditioning load for all blowing conditions. The airconditioning load varied from $320 \mathrm{~W}$ to $1,600 \mathrm{~W}$ depending on the blowing condition. The higher airconditioning load was derived for a larger air flow rate and a high air flow temperature. The energy consumption in the steady state is shown in Figure 15. The airconditioning load after 10 mins was larger than in the steady state, even under the same blowing conditions, 


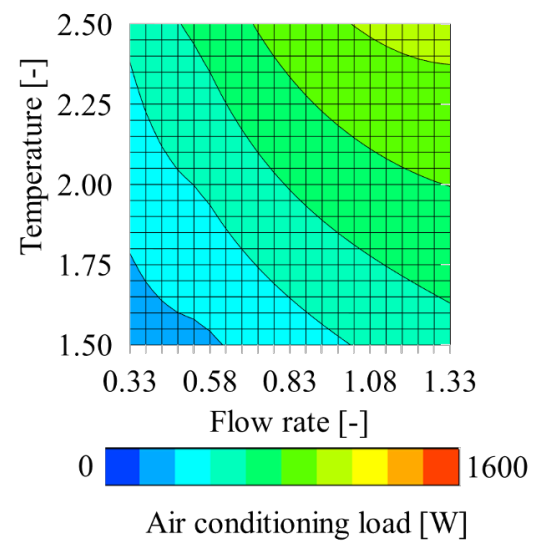

Fig. 15 Amount of energy consumed in the steady state

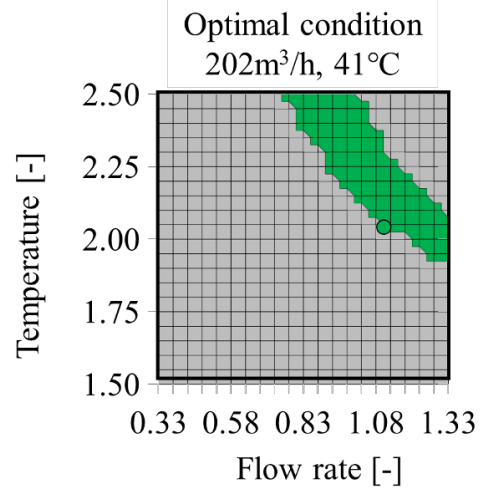

Fig. 16 Optimal condition after 10 mins

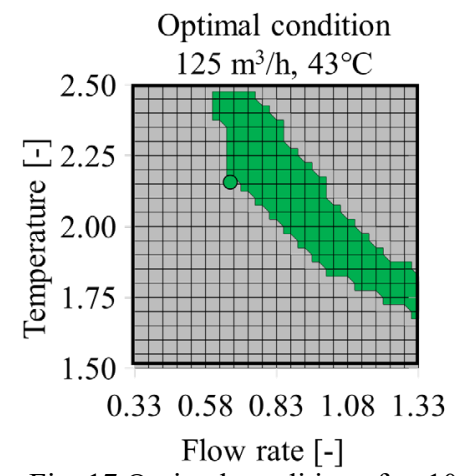

Fig. 17 Optimal condition after 10 mins

\section{Conclusion}

In the present study, transient numerical simulations were performed to determine the optimal blowing conditions that fulfill three objective functions: defogging performance, thermal comfort, and energy savings. As a result, the following conclusions were derived.

1 A middle air flow rate with a high temperature or a high air flow rate with a low temperature are required for defogging within 10 mins after starting.
2 The sensitivities of defogging performance to air flow rate and air temperature depend on the range of blowing conditions and the elapsed time.

3 In order to secure thermal comfort within a short time, a high air flow rate at a high temperature is required.

4 The dependences of the equivalent temperature on the air flow rate and air temperature are comparable.

5 An optimized control strategy for the blowing condition was proposed: airflow temperature was fixed around at $40{ }^{\circ} \mathrm{C}$ throughout running and the air flow rate was decreased from $200 \mathrm{~m}^{3} / \mathrm{h}$ at the beginning to $125 \mathrm{~m}^{3} / \mathrm{h}$ after 10 mins.

\section{References}

1. A. Aroussi, A. Hassan, and Y. Morsi, Heat and Mass Transfer 39, 5-6, 401-405, (2003)

2. M.H. Shojaeefard, G.R. Molaeimanesh, N. Aghamirzaei, S. Ghezelbiglo, and B. Zeinolabedini, International Journal of Automotive Engineering, $5,4,(2015)$

3. ISO 7730, 2005, Ergonomics of the thermal environment - Analytical determination and interpretation of thermal comfort using calculation of the PMV and PPD indices and local thermal comfort criteria, (2005)

4. T. Kubota, T. Ishikawa, J. Tosaka, and H. Okayasu, SAE Technical Paper 2018-01-0064, (2018)

5. M.A. Fayazbakhsh and M. Bahrami, SAE Technical Paper, (2013)

6. T. Ono, Y. Tanoue, H. Nagano, I. Kohri, S. Shiratori, K. Shimano, and S. Kato, JSAE Annual Congress (Spring), (2018)

7. O. Tetens, Zeitschrift fur Geophysik, 6, 297-309, (1930)

8. JIS D4502: Passenger cars-Windshield demisting system (1994)

9. Council Directive 78/317/EEC of 21 December 1977', Official Journal, L 081, 27-48, (1978)

10. 'US Department of Transportation, National Highway Traffic Safety Administration, Laboratory Test Procedure for FMVSS 103, windshield defrosting and defogging systems', TP-103-13, (1996)

11. ISO 14505-2: Ergonomics of the thermal environment - Evaluation of thermal environments in vehicles - Part 2: Determination of equivalent temperature, (2006)

12. H. Nagano, T. Ono, R. Okabe, I. Kohri, S. Shiratori, K. Shimano, JSAE Annual congress (Autumn), (2018)

13. S. Tanabe, E.A. Arens, F. Bauman, ASHRAE Transactions, 100 Part 1, (1994)

14. The Society of Heating, Air-Conditioning and Sanitary Engineers of Japan., Maruzen Publishing Co., Ltd., (2018)

15. H. Nagano, S. Kato, Z, Shengwei, Y. Ozeki, K. Matsunaga, T. Kataoka, SAE International Journal of Passenger Cars - Mechanical Systems, (2008) 